\title{
Spontaneous action potentials and circumnutation in Helianthus annuus
}

\author{
Maria Stolarz $^{1} \cdot$ Halina Dziubińska ${ }^{1}$
}

Received: 17 October 2016/Revised: 24 June 2017/ Accepted: 7 September 2017/Published online: 16 September 2017

(C) The Author(s) 2017. This article is an open access publication

\begin{abstract}
Action potentials (APs) in plants are involved in fast leaf or trap closure as well as elongation, respiration, photosynthesis, and fertilization regulation. Here, spontaneous APs (SAPs) in relation to endogenous stem movement named circumnutation $(\mathrm{CN})$ have been investigated in Helianthus annuus in different light conditions in freely circumnutating and immobilized plants. Extracellular electrical measurements and time-lapse photography were carried out simultaneously. The parameters of CN (trajectory length, period, and direction) and the number and transmission direction of SAPs were analysed. In continuous light $\left(25-40 \mu \mathrm{mol} \mathrm{m} \mathrm{m}^{-2} \mathrm{~s}^{-1}\right)$, all plants circumnutating vigorously in a regular elliptical manner and no SAPs were observed. In light/dark conditions, the plants circumnutated in a daily pattern, most SAPs were observed in the dark and freely circumnutated sunflowers had two times more SAPs (10 SAPs/24 h/plant) than the immobilized plants (5 SAPs/24 h/plant). In continuous very low light $\left(5 \mu \mathrm{mol} \mathrm{m} \mathrm{m}^{-2} \mathrm{~s}^{-1}\right)$, the plants circumnutated weakly and irregularly and SAPs appeared without the circadian pattern. 3-5 SAPs/24/plant occurred in the freely circumnutating and immobilized plants. In light/dark and continuous very low light conditions, an ultradian rhythm of SAPs was observed and the mean spacing between SAPs
\end{abstract}

Communicated by J. Kovacik.

Electronic supplementary material The online version of this article (doi:10.1007/s11738-017-2528-0) contains supplementary material, which is available to authorized users.

Maria Stolarz

maria.stolarz@poczta.umcs.lublin.pl

1 Department of Biophysics, Institute of Biology and Biochemistry, Maria Curie-Skłodowska University, Akademicka 19, 20-033 Lublin, Poland was approx. 121-271 $\mathrm{min}$ in the freely circumnutating and immobilized plants. Under all light conditions, more SAPs were transmitted basipetally than acropetally. One-hour lasting series of 3-4 min spaced SAPs locally propagated were observed as well in very low light. Basipetal and acropetal SAPs passing along the stem motor region accompany irregularity, changes in the $\mathrm{CN}$ trajectory direction, and stem torsion. These results demonstrate that APs and $\mathrm{CN}$ changes play a role in plant adaptation to light conditions and that there is an ultradian rhythm of SAPs beside ultradian $\mathrm{CN}$ rhythm.

Keywords Action potential - Circumnutation - Daily rhythm - Growth - Light - Spontaneous action potential . Time lapse $\cdot$ Ultradian rhythm
Abbreviations
$\mathrm{CN}$ Circumnutation
cw Clockwise
ccw Counterclockwise
SAP Spontaneous action potential

\section{Introduction}

In plants, APs-long-distance electrical signals-are induced by a variety of stimuli, e.g. light, shadow, wounding, touch, temperature, or chemicals (glutamate, potassium chloride) (Dziubinska 2003; Fromm and Lautner 2007; Król et al. 2010; Mousavi et al. 2013; SalvadorRecatala et al. 2014; Salvador-Recatala 2016). They are involved in fast leaf or trap closure, elongation, regulation of respiration and fertilization, and gene expression (Dziubinska 2003; Fromm and Lautner 2007; Król et al. 2010). The involvement of APs in fast leaf and trap closure in 
sensitive plants Mimosa pudica and Dionaea muscipula is the best-visible and evident effector response in plants (Sibaoka 1991; Krol et al. 2012). Besides the stimuli-induced APs, there are SAPs described 20 years ago by Zawadzki et al. (1995). They appear under lack of external stimuli and their source is unknown. Spontaneous APs (SAPs) have lately been observed in Solanum lycopersicum plants (Macedo et al. 2015) and in Helianthus annuus (Zawadzki et al. 1995), which is also known to exhibit intense and varied endogenous movements named circumnutation $(\mathrm{CN})$. CNs are commonly observed in growing plants (Darwin and Darwin 1880); they vary during different stages of plant growth, and exhibit an ultradian, daily, and circadian rhythm as well as complex geometrical patterns (Buda et al. 2003; Charzewska and Zawadzki 2006). $\mathrm{CN}$ is an endogenous movement modulated by multiple stimuli, e.g. light, wounding, touch, temperature, chemicals, and gravity (Buda et al. 2003; Hayashi et al. 2004; Charzewska and Zawadzki 2006; Stolarz et al. 2010). The same stimuli also trigger APs, as mentioned above; therefore, the search for relationships between endogenous $\mathrm{CN}$ and excitation in plants is advisable. Our previous studies showed the effect of glutamate and lithium on CN. Glutamate-induced series of APs differ in vigorously and weakly circumnutating sunflower seedlings treated with lithium (Stolarz et al. 2015). Sunflowers with a lithium-induced decrease in the circumnutation intensity had an increased number of APs in Glu-induced series. Recently, we have shown that the ultradian oscillations of the membrane potential (depolarisation and hyperpolarisation) accompany $\mathrm{CN}$ as well (Kurenda et al. 2015). Additionally, the same ion channel and proton pump inhibitors modulating excitation in plants modulate $\mathrm{CN}$ as well (Millet and Badot 1996; Krol and Trebacz 2000; Krol et al. 2006; Kurenda et al. 2015).

The ability to respond to changing light environmental conditions and light stimuli is a key feature in a photosynthesising organism. Light intensity and photoperiod changes mainly affect not only photosynthesis but also organ movements and excitability (Zawadzki et al. 1995; Stankovic et al. 1998; Buda et al. 2003; Charzewska and Zawadzki 2006). The aim of this study was to investigate the relation between CN (Appendix S1) and SAPs in different light conditions using extracellular electrical measurements and time-lapse photography in $H$. annuus plants. To our knowledge, the influence of light on plant spontaneous excitation and its relation to $\mathrm{CN}$ movement have not been described so far. We have shown for the first time an ultradian rhythm of the long-distance SAPs beside the CN rhythm and SAPs accompanying the irregularity of the $\mathrm{CN}$ trajectory in very low light conditions. Additionally, it was shown that the number of SAPs is higher in freely circumnutating sunflower, compared with immobilized plants.

\section{Materials and methods}

\section{Experimental plants}

The studies were carried out on 20-30-day-old Helianthus annuus L. plants (PNOS, Ożarów Maz. Poland) grown in a vegetation room in pots filled with garden soil. They were watered with tap water and no other treatment was applied. A 16:8-h light:dark (04:00-20:00) photoperiod was maintained. The intensity of white light in the PAR range (Power Star HQT-T400W/DOSRAM GmbH, Munich, Germany) at the level of plant leaves was approximately $70 \mu \mathrm{mol} \mathrm{m} \mathrm{m}^{-2} \mathrm{~s}^{-1}$. The vegetation room was air-conditioned; the temperature was $24 \pm 1{ }^{\circ} \mathrm{C}$ and humidity $50-70 \%$. Approximately $20-35-\mathrm{cm}$-high plants with one or two pairs of developed leaves were taken for the experiments. To examine the relationship between $\mathrm{CN}$ and SAPs, freely circumnutating and immobilized sunflowers were used for measurements (Fig. 1a). The stem of the immobilized sunflowers was tied to a wooden pole for prevention of $\mathrm{CN}$.

\section{Circumnutation measurements-time-lapse method}

The H. annuus plant was filmed in a Faraday cage with simultaneous electrophysiological measurements. A top view monochromatic camera (Mintron MTV-1368CD, Mintron Enterprise Co. Ltd, Taipei, Taiwan) was used to record the trajectory movement of the stem apex. For filming in darkness, very dim green light with intensity $<0.1 \mu \mathrm{mol} \mathrm{m} \mathrm{m}^{-2} \mathrm{~s}^{-1}$ PAR (25 1.I Pila, Poland) was used. Time-lapse images were recorded at a rate of one frame per minute or five minutes by Gotcha!Multicam software (Prescient System Inc., West Chester, PA, USA). The system was calibrated by a millimetre scale placed at the level of the pot. The time-lapse images were digitized using Circumnutation Tracker (Stolarz et al. 2014). Experimental points (coordinates $x, y$ of the stem apex on the horizontal plane) were determined at 1- or 5-min intervals. The $\mathrm{CN}$ length (the distance that the organ apex covers during a single $\mathrm{CN}$ cycle) and the $\mathrm{CN}$ period (the time that the organ apex needs to trace a single circumnutation cycle) were calculated by Circumnutation Tracker software (Stolarz et al. 2014).

\section{Electrophysiological measurements-extracellular method}

The measurements were carried out in the laboratory in a Faraday cage. Changes in the electrical potential were measured with four extracellular $\mathrm{Ag} / \mathrm{AgCl}$ electrodes (silver wire, $0.2 \mathrm{~mm}$ diameter, World Precision Instruments, 
Fig. $1 \mathrm{CN}$ and SAPs in $H$. annuus. a Example of a $H$. annuus plant, top and side view (an example of a circumnutating plant is shown in Appendix S1), and electrode arrangement in extracellular SAP measurements. Four $\mathrm{Ag} / \mathrm{Cl}$ electrodes $(1,2,3,4)$ were inserted across the stem. The reference (ref) electrode was inserted at the base of the stem. An immobilized sunflower-in the lower right corner. b Top view of $\mathrm{CN}$ regular (continuous light) and irregular (continuous very low light) stem apex trajectory, examples of approx. 24-h records (Appendix S2). c Examples of basipetally and acropetally transmitted SAPs along the stem
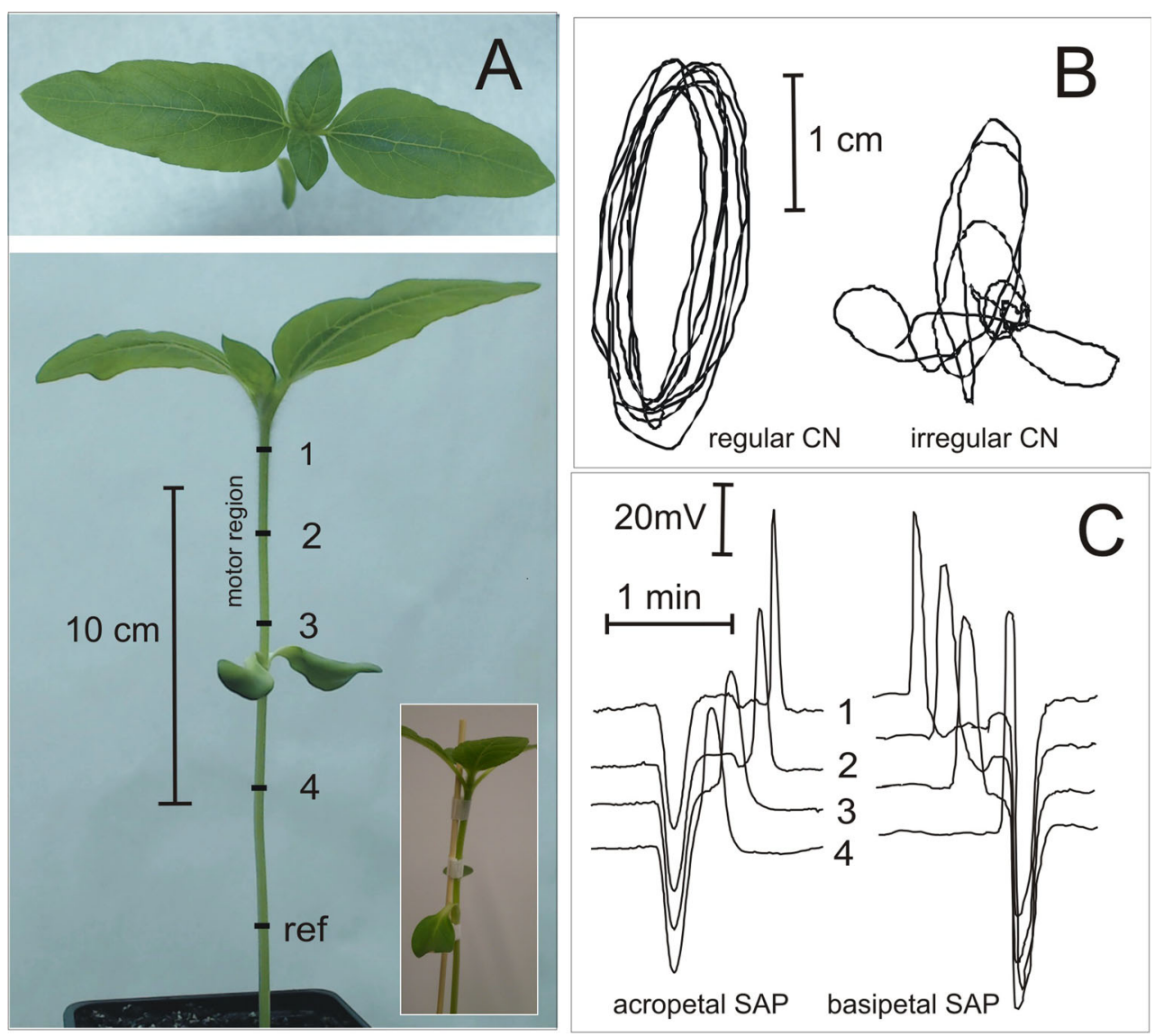

Sarasota, FL, USA) inserted across the sunflower stem and then interfaced with a multi-channel data acquisition system composed of a differential amplifier (ME-4600 Meilhaus, Germany) and RealView software (Abacom, Germany). During the preparation of the $\mathrm{Ag} / \mathrm{AgCl}$ electrodes, the silver wire was electrolytically coated with silver chloride. A reference electrode of the same type as the measuring electrodes was placed in the base of the stem. The long-distance SAPs pass by electrodes 1, 2, 3, 4 and the reference, basal electrode; therefore, the reference electrode is a relative reference electrode because they pass through it. The local, apical SAPs pass only by electrodes 1 and 2 and they never reach the reference, basal electrode; hence, the reference electrode in this case is an absolute reference electrode. The frequency of sample recording was $1 \mathrm{~Hz}$. The arrangement of the electrodes on the sunflower is shown in Fig. 1a. The SAP interval, i.e. the time spacing between two subsequent SAPs was calculated.

\section{Experimental variants}

The measurements were carried out in three different light conditions: light/dark: $16 \mathrm{~h}$ of $25-40 \mu \mathrm{mol} \mathrm{m}{ }^{-2} \mathrm{~s}^{-1} / 8 \mathrm{~h}$ darkness, continuous light: $25-40 \mu \mathrm{mol} \mathrm{m}{ }^{-2} \mathrm{~s}^{-1}$, and continuous very low light: $5 \mu \mathrm{mol} \mathrm{m}{ }^{-2} \mathrm{~s}^{-1}$ in PAR range white light (Power Star HQT-T400W/DOSRAM GmbH, Munich, Germany) and a temperature of $24 \pm 1{ }^{\circ} \mathrm{C}$. Freely circumnutating sunflowers and those with circumnutation prevented by stem immobilization were investigated.

\section{Data analyses}

Ten plants were investigated in each of the variants of the experiments and the results are presented as the mean \pm SE. The data were analysed using Statistica ver. 12 software (StatSoft, Inc. 2014). The data set was first tested for normality using Shapiro-Wilk test and homogeneity of variance was assessed with Levene's test. All data had non-normal distribution and unequal variance; therefore, non-parametric Kruskal-Wallis ANOVA was used. Multiple comparisons of the mean ranks for all groups (pairwise analysis) were used. The level of statistical significance for all tests was set at $p<0.05$.

\section{Results}

The sunflower plants circumnutated (Appendix S1) in an approx. 2-3 h ultradian rhythm and the $\mathrm{CN}$ trajectory had a regular or irregular pattern (Fig. 1b; Appendix S2). 


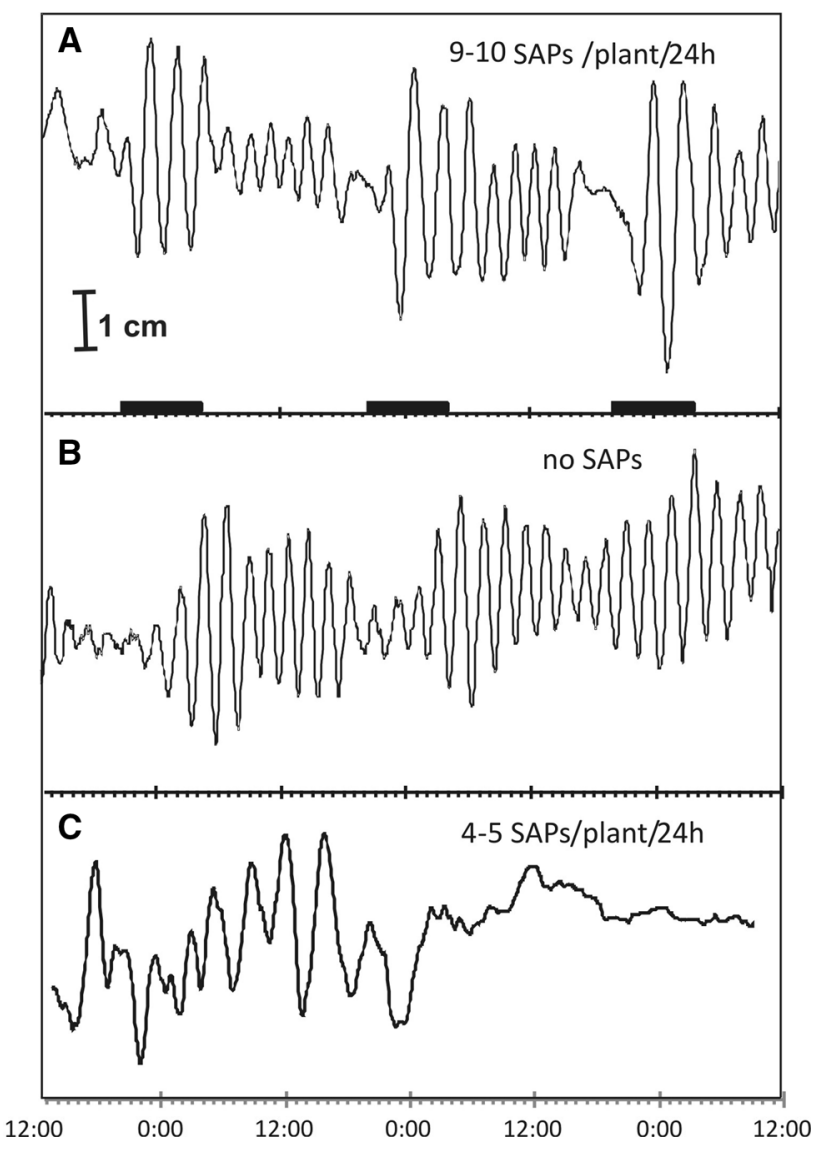

Fig. 2 Examples of $\mathrm{CN}$ in different light conditions in freely circumnutating $H$. annuus. The plot is an $x$ - or $y$-coordinate projection on the time course from a top-view recording. a Light/dark: $16 \mathrm{~h}$ of 25-40 $\mu \mathrm{mol} \mathrm{m} \mathrm{m}^{-2} \mathrm{~s}^{-1} / 8 \mathrm{~h}$ darkness, light-on 04:00 light-off 20:00. b Continuous light: $25-40 \mu \mathrm{mol} \mathrm{m}^{-2} \mathrm{~s}^{-1}$. c Continuous very low light: $5 \mu \mathrm{mol} \mathrm{m} \mathrm{m}^{-2} \mathrm{~s}^{-1}$

Simultaneously, spontaneous electrical changes in a form of a 5-60 mV 1-min-long-lasting SAPs were recorded. A typical graphic example of SAPs transmitted basipetally and acropetally along the sunflower stem is shown in Fig. 1c. The CN length and period as well as the number and transmission direction of SAPs were different in the different light conditions. Vigorous $\mathrm{CN}$ or their arrest was observed (Fig. 2) and no SAPs or single acropetally or basipetally transmitted SAPs (Fig. 1c) and even series of APs were recorded. The $\mathrm{CN}$ and SAP parameters in light/dark cycles, continuous light $\left(25-40 \mu \mathrm{mol} \mathrm{m}{ }^{-2} \mathrm{~s}^{-1}\right)$ and continuous very low light $\left(5 \mu \mathrm{mol} \mathrm{m} \mathrm{m}^{-2} \mathrm{~s}^{-1}\right)$ in freely circumnutating and immobilized sunflowers are shown in Table 1 (Supplementary Table 1 and Supplementary Table 2).

\section{Ultradian and daily rhythm of CN and SAPs in light/dark conditions}

In light/dark conditions, the ultradian rhythm and daily $\mathrm{CN}$ pattern appeared; an example is shown in Fig. 2a. Small daily and large nocturnal CNs were observed (Fig. 3a). In those plants, approx. $9.8 \pm 1(N=30) \mathrm{SAPs} /$ day/plant were generated (Table 1) mainly during the dark period, which is shown in Fig. 3a. The number of SAPs emerging during 3-h intervals was calculated, and an evident daily rhythm was revealed. The greatest number of SAPs preceded the maximal-length $\mathrm{CNs}$ by approx. $3 \mathrm{~h}$. It was found that the interval between SAPs in the light/dark conditions was on average $121 \pm 9 \min (n=266)$ and was nearing the $\mathrm{CN}$ period, which was $143 \pm 1 \mathrm{~min}$ ( $n=293$ ) (Table 1). In the immobilized sunflower, the number of SAPs/day/plant was halved significantly $(4.6 \pm 0.6(N=28) \mathrm{SAPs} /$ day/plant $)$ and the SAPs interval was doubled $[237 \pm 30 \mathrm{~min}(n=118)]$. In free $\mathrm{CN}$, similar to the immobilized plants, approx. $60-70 \%$ of the SAPs were generated in the upper part of the plant (leaves and stem apex) and approx. 25\% in the lower part of the plant. Beside acropetally or basipetally propagated SAPs, occasional acropetal-basipetal SAPs were recorded (10-20\%, Table 1). The acropetal-basipetal SAPs originated from some place along the stem and propagated from that place acropetally and basipetally simultaneously, presumably through some phloem vessels or in one direction only, and later in the opposite direction along different vessels that were not excited before. Refractoriness would not allow basipetal transmission followed promptly by acropetal transmission (or vice versa). Propagation velocity of basipetally and acropetally propagated SAPs was approx. $8-19 \mathrm{~cm} \mathrm{~min}^{-1}$ (Supplementary Table 2). It is known that light-off and light-on evoke $\mathrm{CN}$ disturbance (Stolarz et al. 2008) and AP induction (Stankovic et al. 1998; Stahlberg et al. 2006; Król et al. 2010); therefore, to exclude this stimulus and ensure constant environmental conditions, we applied continuous light to study the relation between SAPs and CN.

\section{Vigorous CNs in continuous light but no SAPs}

In continuous light $\left(25-40 \mu \mathrm{mol} \mathrm{m} \mathrm{m}^{-2} \mathrm{~s}^{-1}\right)$, the sunflower circumnutates vigorously in a regular elliptical manner (Fig. 2b; Table 1) but does not generate SAPs. This complete lack of SAPs under continuous light in the presence of vigorous $\mathrm{CN}$ indicates that SAP does not play a role in the basic mechanism generating $\mathrm{CN}$ and SAPs are not induced by $\mathrm{CN}$ at this light intensity. In the immobilized sunflower, SAPs were absent as well. To evoke the SAP phenomenon, continuous very low light was applied in the next experiments. 
Table 1 Parameters of circumnutation $(\mathrm{CN})$ and spontaneous action potentials (SAPs) in H. annuus in different light conditions

\begin{tabular}{|c|c|c|c|c|c|c|c|}
\hline \multirow[t]{2}{*}{ Variable } & \multicolumn{2}{|l|}{ Light/dark } & \multicolumn{2}{|c|}{ Continuous light } & \multicolumn{2}{|c|}{ Continuous very low light } & \multirow[t]{2}{*}{$p$ value $^{\mathrm{A}}$} \\
\hline & Freely CN & Immobilized & Freely $\mathrm{CN}$ & Immobilized & Freely $\mathrm{CN}$ & Immobilized & \\
\hline $\mathrm{CN}$ length $(\mathrm{mm})$ & $\begin{array}{l}39 \pm 2^{\mathrm{a}} \\
\quad(n=293)\end{array}$ & - & $\begin{array}{l}41 \pm 2^{\mathrm{a}} \\
\quad(n=285)\end{array}$ & - & $\begin{array}{l}19 \pm 2^{\mathrm{b}} \\
\quad(n=152)\end{array}$ & - & $0.0000 / * * *$ \\
\hline $\mathrm{CN}$ period $(\min )$ & $\begin{aligned} 143 & \pm 1^{\mathrm{a}} \\
(n & =293)\end{aligned}$ & & $\begin{aligned} 141 & \pm 1^{\mathrm{a}} \\
(n & =285)\end{aligned}$ & & $\begin{aligned} 171 & \pm 6^{\mathrm{b}} \\
(n & =152)\end{aligned}$ & & $0.0035 / * *$ \\
\hline SAP interval (min) & $\begin{aligned} 121 & \pm 9^{\mathrm{a}} \\
(n & =266)\end{aligned}$ & $\begin{aligned} 237 & \pm 30^{\mathrm{b}} \\
(n & =118)\end{aligned}$ & - & - & $\begin{aligned} 259 & \pm 22^{\mathrm{c}} \\
(n & =120)\end{aligned}$ & $\begin{aligned} 271 & \pm 35^{\mathrm{b}, \mathrm{c}} \\
(n & =55)\end{aligned}$ & $0.0000 / * * *$ \\
\hline SAP number/day/plant & $\begin{array}{l}9.8 \pm 1^{\mathrm{a}} \\
\quad(N=30)\end{array}$ & $\begin{array}{r}4.6 \pm 0.6^{\mathrm{b}} \\
(N=28)\end{array}$ & & & $\begin{array}{r}4.8 \pm 0.6^{\mathrm{b}} \\
(N=29)\end{array}$ & $\begin{array}{l}3.5 \pm 0.6^{\mathrm{b}} \\
(N=18)\end{array}$ & $0.0000 / * * *$ \\
\hline Basipetal SAPs (\%) & 58 & 68 & & & 73 & 77 & \\
\hline Acropetal SAPs (\%) & 25 & 23 & & & 20 & 14 & \\
\hline $\begin{array}{l}\text { Acropetal-basipetal } \\
\text { SAPs }(\%)\end{array}$ & 17 & 9 & & & 7 & 9 & \\
\hline $\begin{array}{l}\text { Number of plants } \\
\text { investigated }\end{array}$ & 10 & 10 & 10 & 10 & 10 & 10 & \\
\hline$\%$ of plants with SAPs & 100 & 100 & 0 & 0 & 100 & 80 & \\
\hline
\end{tabular}

Plants were freely circumnutating or immobilized by stem tied to a wooden pole. Light/dark: $16 \mathrm{~h}$ of $25-40 \mu \mathrm{mol} \mathrm{m} \mathrm{m}^{-2} \mathrm{~s}^{-1} / 8 \mathrm{~h}$ darkness, continuous light: $25-40 \mu \mathrm{mol} \mathrm{m}{ }^{-2} \mathrm{~s}^{-1}$, continuous very low light: $5 \mu \mathrm{mol} \mathrm{m} \mathrm{m}^{-2} \mathrm{~s}^{-1}$. Experiments lasted 3 days. The CN length is the length of the trajectory of $\mathrm{CN}$. The $\mathrm{CN}$ period is the time needed by the organ apex to trace a single $\mathrm{CN}$ cycle. The SAP interval is the time spacing between two subsequent SAPs. Basipetal SAPs are SAPs propagating downwards the stem; acropetal SAPs are SAPs propagating upwards the stem; acropetal-basipetal SAPs are SAPs propagating upwards and downwards the stem. $n$ number of cycles, $N$ number of days, - lack of SAPs or $\mathrm{CN}$

${ }^{A} p$ value/***-statistical significance in the Kruskal-Wallis ANOVA tests. The different letters denote significant differences between groups (within one variable). Multiple comparisons of mean ranks for all groups (pairwise analysis) were used. The level of statistical significance for all tests was set at $p<0.05$. Values represent mean \pm standard error. $* * p<0.01 ; * * * p<0.001$

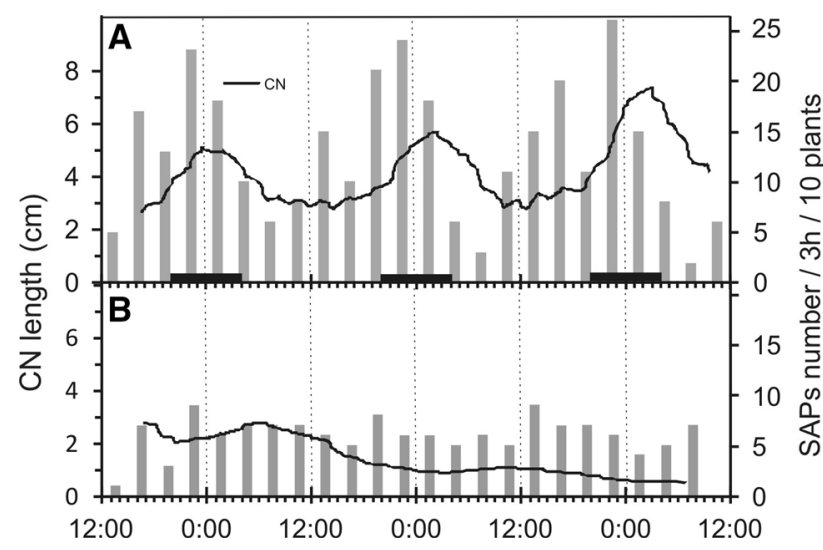

Fig. 3 Comparison of the $\mathrm{CN}$ length and number of SAPs in $H$. annuus. The number of SAPs for 3-day extracellular measurements was calculated at 3 -h intervals $(12: 00-15: 00$, 15:00-18:00, 18:00-21:00...) in ten plants (column). The CN length is the length of the trajectory of $\mathrm{CN}$, the plot is a moving average of a 3-h window from ten plants (line). a Light/dark: $16 \mathrm{~h}$ of $25-40 \mu \mathrm{mol} \mathrm{m} \mathrm{m}^{-2} \mathrm{~s}^{-1} / 8 \mathrm{~h}$ darkness, light-on 04:00 light-off 20:00. b Continuous very low light: $5 \mu \mathrm{mol} \mathrm{m} \mathrm{m}^{-2} \mathrm{~s}^{-1}$

\section{SAP ultradian rhythm and $\mathrm{CN}$ irregularity in continuous very low light conditions}

In continuous very low light $\left(5 \mu \mathrm{mol} \mathrm{m} \mathrm{m}^{-2} \mathrm{~s}^{-1}\right)$, the $\mathrm{CNs}$ were weak and irregular as shown in Appendix S3 and Appendix S4 and in Table 1, Figs. 2c, 3b and 4. During the second day, there were many $\mathrm{CN}$ disturbances and during the third day CNs were usually arrested. The number of SAPs on average was approx. $4-5 \mathrm{SAPs} / 24 \mathrm{~h} /$ plant during all days of the experiments, even during the third day of the $\mathrm{CN}$ arrest. The relation of the $\mathrm{CN}$ length vs. the SAP number is shown in Fig. 3b. Examples of an irregular CN trajectory and simultaneous SAP emergence are shown in Fig. 4a-d. Many SAPs emerge during maximum stem bending. The examples of SAP occurrence followed by $\mathrm{CN}$ direction changes are shown in Fig. 4e-h and, respectively, in Appendix S5 and Appendix S6. It is noticeable, therefore, that in very low light SAPs accompany the irregular CNs. Another type of stem movement changes is the 2-4$\mathrm{mm}$ stem "torsion" shown in video Appendix S7 and Appendix S8 (marked by a red point) accompanied by SAPs propagating acropetally along the stem. "Torsion" is a sudden twitch against the background of the slow circumnutation movement of the plant. 
Fig. 4 The $\mathrm{CN}$ and appearance of SAPs in $H$. annuus plants in very low light

$\left(5 \mu \mathrm{mol} \mathrm{m} \mathrm{m}^{-2} \mathrm{~s}^{-1}\right)$. The plots are the $x$ - and $y$-coordinate projection on the time course (a, $\mathbf{c}, \mathbf{e}, \mathbf{f})$ or the top view of the $\mathrm{CN}$ trajectory $(\mathbf{b}, \mathbf{d}, \mathbf{f}, \mathbf{h})$. Black point marks the moment of SAP appearance. The arrow marks the beginning of $\mathrm{CN}$, dashed line-trajectory of $\mathrm{CN}$ after SAP. a-d Examples of weak and irregular $\mathrm{CN}$ associated with SAPs passing along the stem motor region. Highly excitable plants are presented with more SAPs than the average SAP number. Examples of circumnutating plants are shown in Appendix S3 and Appendix S4, respectively. eh Examples of $\mathrm{CN}$ direction changes after acropetal SAP passing along the motor region. Examples of circumnutating plants are shown in Appendix S5 and Appendix S6, respectively

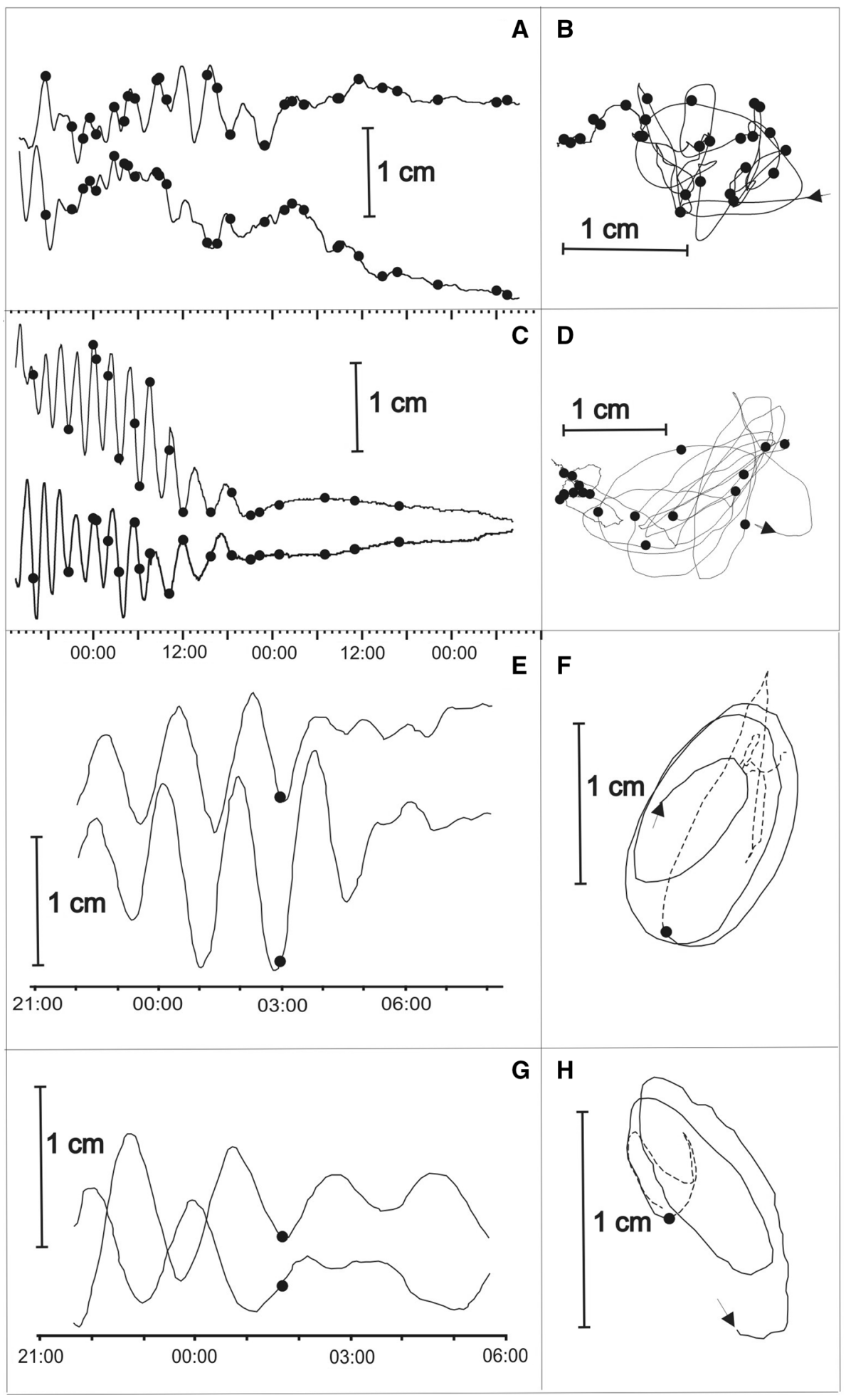

It was found that in very low light conditions in a free$\mathrm{CN}$ sunflower the number of SAPs/day/plant was $4.8 \pm 0.6$ $(N=29)$ and the interval between all SAPs was on average $259 \pm 22 \min (n=120)$ and these were similar as in the immobilized sunflower (Table 1). In the freely $\mathrm{CN}$ plants, two kinds of series of SAPs were observed: ultradian series of long-distance transmitted SAPs and series of local SAPs. The series consisting of 2-7 SAPs with, on average, $159 \pm 8 \min (n=75)$ intervals between them were recorded and named ultradian series of SAPs (Table 2). Examples of the ultradian SAPs are presented in Fig. 5. The intervals between the SAPs were the same as 
Table 2 Spontaneous excitation in $H$. annuus under very low light $\left(5 \mu \mathrm{mol} \mathrm{m}{ }^{-2} \mathrm{~s}^{-1}\right)$

\begin{tabular}{lll}
\hline & Ultradian series of long-distance SAPs & Series of local SAPs \\
\hline Number of APs in a series & $2-7$ & $6-32$ \\
Interval between APs & Approx. $160 \mathrm{~min}$ & $3-4 \mathrm{~min}$ \\
Series duration & $2-20 \mathrm{~h}$ & $0.3-2 \mathrm{~h}$ \\
Propagation & Along whole stem (approx. 20-35 cm) & Along upper part of stem (approx. 5 cm) \\
\hline
\end{tabular}

Examples of ultradian series of long-distance SAPs in Fig. 5. Examples of series of local SAPs in Fig. 6
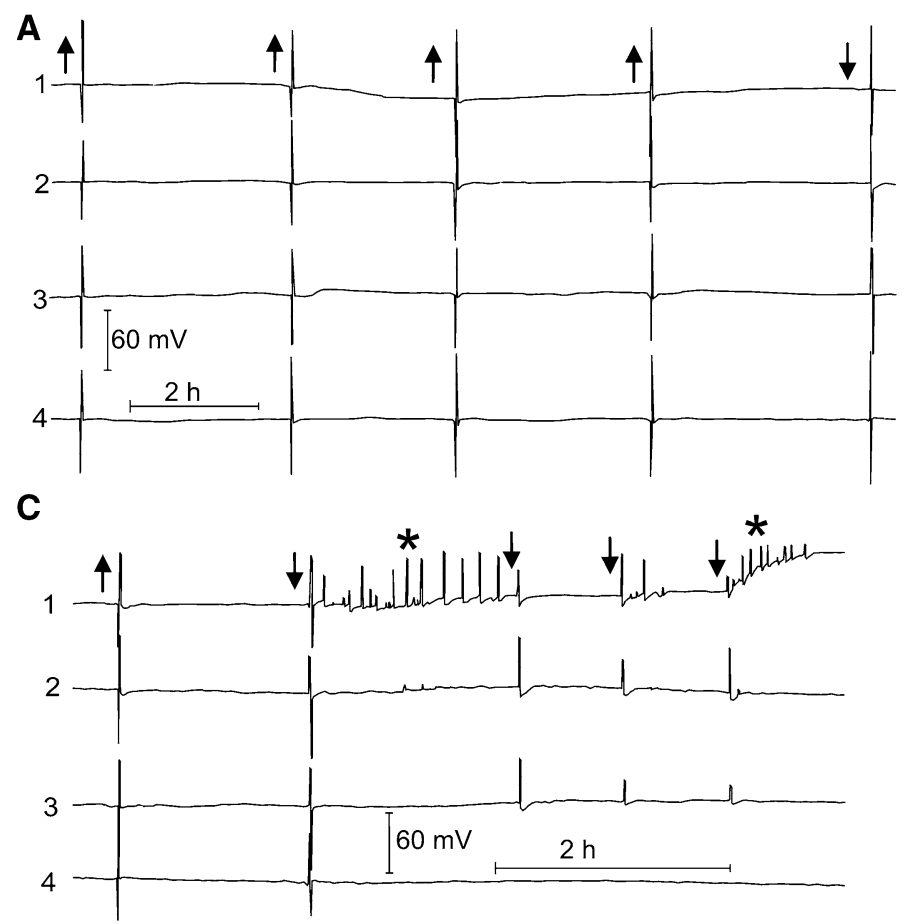

Fig. 5 Ultradian series of long-distance-propagated SAPs in $H$. annuus plants in very low light $\left(5 \mu \mathrm{mol} \mathrm{m} \mathrm{m}^{-2} \mathrm{~s}^{-1}\right)$. Examples of traces from an extracellular electrical recording. Electrode (1, 2, 3, 4) arrangement shown in Fig. 1a. Arrow up-acropetally transmitted

the $\mathrm{CN}$ period, i.e. $171 \pm 6 \min (n=152)$ (Table 1). The ultradian SAPs propagated throughout whole stem; they were registered by electrodes 1, 2, 3, 4 and the reference electrode (Fig. 5). In low-light condition, $73 \%$ of APs were generated in the upper part of the sunflower (leaves and stem apex) and transmitted basipetally and $20 \%$ of APs were generated in the lower part of the plant and transmitted acropetally. Additionally, during the third day of the experiment, series of locally propagated APs appeared in some plants as shown in Fig. 6 and Table 2. They persisted on average for $66 \pm 7 \mathrm{~min}$ and consisted of $18 \pm 2$ SAPs $(n=15$ series); there was a correlation between the duration of the series and the number of APs (Fig. 7). During the approx. 1-h-long local series, the sunflower generated SAPs at ca. 3-4-min intervals.
B
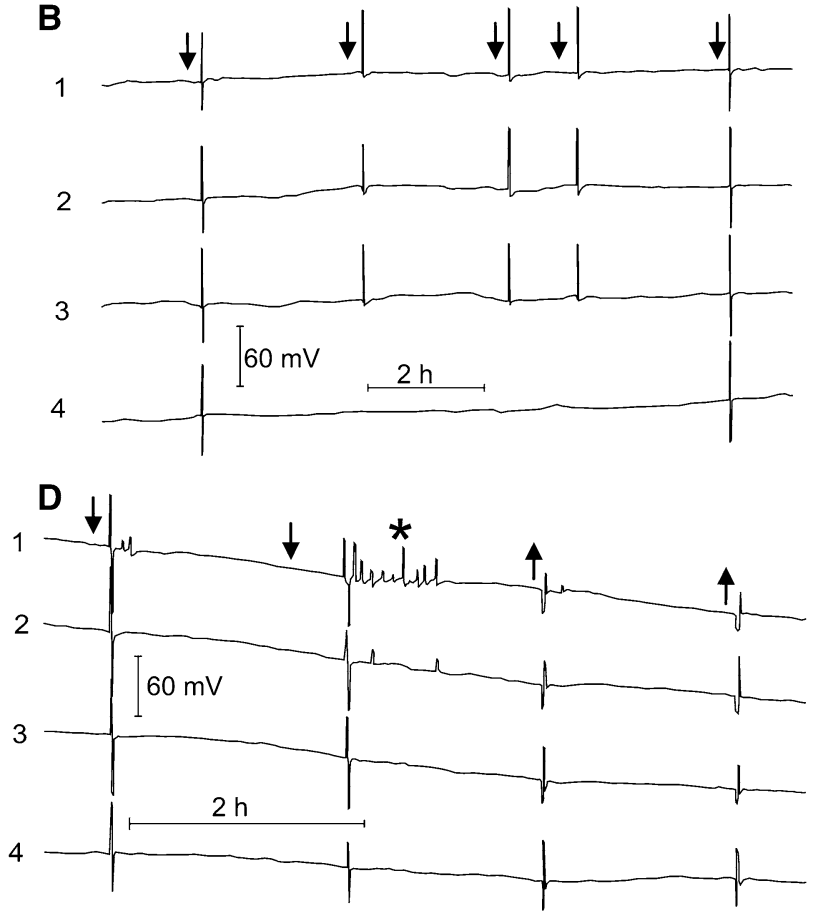

SAP, arrow down-basipetally transmitted SAP. a, b Ultradian, longdistance-propagated SAPs, c, d Ultradian, long-distance-propagated SAPs and series of local SAPs. Examples of a local series of SAPs are marked by asterisks

When transferred back to the vegetation room, plants kept for 3 days in the very low light began flowering after 2 months.

\section{Discussion}

\section{SAP-associated light/dark sensing}

Active movements in plants are a way of adaptation to the changing light conditions in the environment. The examples include, e.g. the widely spread phenomena of tropism and nastic movements as in the pulvinus-driven leaf movement after illumination or darkening in Samanea, Phaseolus, Oxalis, and Desmodium (Moshelion et al. 2002; Moran 2007). H. annuus is a common sun-tracing plant, 


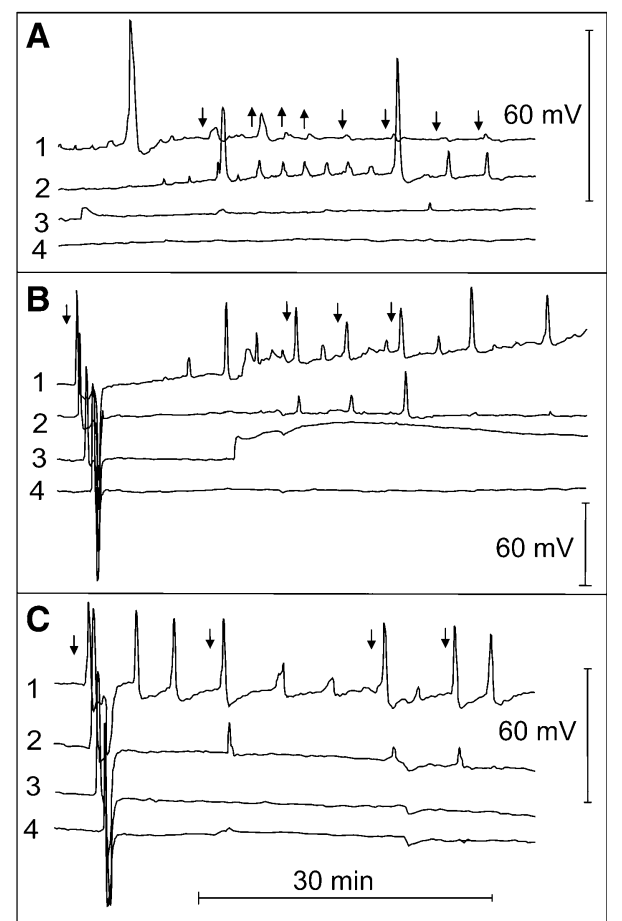

Fig. 6 Series of local SAP $H$. annuus plants emerging during the third day of very low light $\left(5 \mu \mathrm{mol} \mathrm{m} \mathrm{m}^{-2} \mathrm{~s}^{-1}\right)$. Electrode arrangement shown in Fig. 1a. Arrow up-acropetally transmitted SAP, arrow down-basipetally transmitted SAP

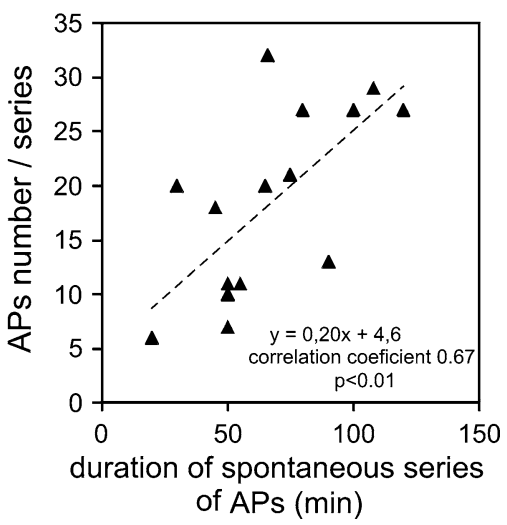

Fig. 7 SAPs and $\mathrm{CN}$ in H. annuus in continuous very low light. The relation between the duration of local series and the number of SAPs. In eight plants, 15 series were observed during the third day under very low light

which moves its stem apex to follow the relative position of the sun (Vandenbrink et al. 2014) and shows an ultradian, daily and circadian rhythm of $\mathrm{CN}$ and $\mathrm{CN}$ disturbance after illumination and darkening (Buda et al. 2003; Charzewska and Zawadzki 2006; Stolarz et al. 2008). There are reports that AP is a light/dark-guided signal in plants (Król et al. 2010). Lately, in S. lycopersicum plants the highest number of SAPs was observed in the early morning (Macedo et al. 2015). Shade and darkness-induced APs were reported also in H. annuus (Stankovic et al. 1998; Stahlberg et al. 2006). Here we have checked the effect of light on plant spontaneous APs and their relation to $\mathrm{CN}$. The light conditions applied here reflect the conditions present in the natural environment and imitate the effect of prolonged shading or cloudy days on plants. The 3-day-long very low light conditions applied here constituted well-tolerated stress because after the treatment plants underwent typical vegetative and generative development after the return to the vegetation room. It has been shown here using long-lasting simultaneous time lapse and extracellular recordings that stem movements $(\mathrm{CN})$ and spontaneous excitation (SAPs) in sunflower plants are light dependent (Table 1). The CN study has shown a regular elliptical or irregular $\mathrm{CN}$ trajectory pattern (Fig. 1b; Appendix S2). Regular ellipses dominated under continuous light while irregularity was observed under light/dark and very low light conditions. The CN irregularity is illustrated in Appendix S3 and Appendix S4 and Fig. 4a-d, respectively. This regular and irregular pattern is related to the absence of SAPs and presence of many SAPs, respectively. The greatest number of SAPs preceded the maximal-length CNs by $3 \mathrm{~h}$ (light/dark, Fig. 3a) and many SAPs appeared at the absence of CNs in very low light (Figs. 3b, 4a, c) and in immobilized plants (Table 1). The daily rhythm of the SAPs number in light/dark condition and the lack of SAPs under continuous light (Table 1) indicate that the light conditions influence the number of SAPs. This is also consistent with the opinion that stronger light decreases excitability (Król et al. 2010). The difference in the number of SAPs in different light conditions (Tables 1,2) should be a suggestion about the information-encoding role of APs in plants.

\section{Spontaneous action potentials}

The circumstances of the occurrence of SAPs and their function are still unclear. It was shown here that SAPs appeared singly or in groups forming ultradian series of long-distance SAPs (Fig. 5) and spontaneous approx. 1-h series of local SAPs (Fig. 6) (Table 2). Here we have shown for the first time the slow approx. 2-4-h ultradian rhythm of SAPs, beside the slow ultradian $\mathrm{CN}$ rhythm. Additionally, another series of local SAPs (Fig. 6) at 3-4min intervals was recorded and they resembled those recorded after glutamate injection (Stolarz et al. 2010, 2015). This confirmed the assumption that there are spontaneous series of APs in plants and that an AP frequency code may exist in plants (Favre et al. 1999; Paszewski et al. 1982). In our study, we observed acropetally or basipetally transmitted SAPs (Fig. 1c). It is probable that SAPs are propagated along the vascular bundle similar to stimuli-induced APs (Dziubińska et al. 2001; Dziubinska 2003; Fromm and Lautner 2007; Salvador-Recatala et al. 
2014; Hedrich et al. 2016). Propagation velocity was approx. 10-20 $\mathrm{cm} \mathrm{min}^{-1}$, typical for sunflower (Zawadzki et al. 1995). Additionally, occasional acropetal-basipetal SAPs were also recorded. They were similar to SAPs described previously by Zawadzki et al. (1995) and APs evoked by glutamate (Stolarz et al. 2010).

\section{SAPs vs. CN}

Zawadzki et al. (1995) found and our present study confirmed the SAP phenomenon, whose physiological function in the sunflower is not determined. Herein, $\mathrm{CN}$ changes accompanied by SAPs were revealed. A daily rhythm of SAPs and CNs (Fig. 3a) and the ultradian interval of the SAP and CN period (Table 1) were shown. Additionally, the example in Fig. 4 shows that SAPs accompany $\mathrm{CN}$ irregularity and a decrease in the $\mathrm{CNs}$ and even changes in the $\mathrm{CN}$ trajectory direction from $c w$ to $c c w$ or vice versa. The sunflower stem "torsion" associated with acropetal SAP passing throughout the motor region was presented in the films (Appendix S7 and Appendix S8). The AP-associated elongation/contraction in H. annuus (Stankovic et al. 1998) and the growth rate inhibition in Luffa cylindrica (Shiina and Tazawa 1986) reported previously support the suggestion that the ultradian SAPs passing throughout the motor region of the stem could disturb a growth-dependent CN. Simultaneously, experiments with immobilized plants showed that freely circumnutating plants had more SAPs than the immobilized plants. This showed that $\mathrm{CN}$ increased the number of SAPs in the sunflower plants. The experiments with inhibited $\mathrm{CN}$ (free-CN and immobilized sunflowers in continuous very low light) demonstrate that CNs are not necessary to appearance of SAPs. On the other hand, sunflower immobilization in light/dark conditions halved the number of SAPs (the number was similar as in the free-CN and immobilized sunflower in continuous very low light); thus, $\mathrm{CN}$ could increase the number of SAPs. This suggested that in light/dark conditions $\mathrm{CN}$ could evoke APs.

The present investigation shows that external conditions can modulate the number of SAPs in $H$. annuus plants and there is a complex relation between the $\mathrm{CN}$ and SAP phenomena and light conditions. The answers to the question if the $\mathrm{CN}$ changes can evoke APs and if APs could evoke $\mathrm{CN}$ changes (as an effector response) need a future investigation.

\section{Conclusions}

In the present work, it has been shown that there is the ultradian SAP rhythm beside the $\mathrm{CN}$ rhythm and the number of SAPs and $\mathrm{CN}$ trajectory changes depends on light conditions. In continuous light, no SAPs under vigorous regular $\mathrm{CN}$ are observed. In continuous very low light conditions, the irregularity of the $\mathrm{CN}$ trajectory is accompanied by SAPs. Presented results showed that SAP appearance and $\mathrm{CN}$ changes play a role in adaptation to very low light conditions in $H$. annuus plants. We believe that in future studies SAPs will be found in other plant species and other stress conditions and that the $\mathrm{CN}$ changes could be a helpful phenomenon for future investigations of the role of long-distance electrical signals in plant behaviour.

Author contribution statement MS designed and carried out the experiments, collected and analysed the results, and wrote the manuscript. HD helped in the analysis of the results and editing the manuscript.

Acknowledgements We thank Professor Kazimierz Trębacz for useful discussions and comments on the manuscript.

Open Access This article is distributed under the terms of the Creative Commons Attribution 4.0 International License (http://crea tivecommons.org/licenses/by/4.0/), which permits unrestricted use, distribution, and reproduction in any medium, provided you give appropriate credit to the original author(s) and the source, provide a link to the Creative Commons license, and indicate if changes were made.

\section{References}

Buda A, Zawadzki T, Krupa M, Stolarz M, Okulski W (2003) Daily and infradian rhythms of circumnutation intensity in Helianthus annuus. Physiol Plant 119:582-589

Charzewska A, Zawadzki T (2006) Circadian modulation of circumnutation length, period, and shape in Helianthus annuus. J Plant Growth Regul 25:324-331

Darwin C, Darwin F (1880) The power of movement in plants. John Murray, London

Dziubinska H (2003) Ways of signal transmission and physiological role of electrical potentials in plants. Acta Soc Bot Polon 72:309-318

Dziubińska H, Trębacz K, Zawadzki T (2001) Transmission route for action potentials and variation potentials in Helianthus annuus L. J Plant Physiol 158:1167-1172

Favre P, Zawadzki T, Dziubinska H, Trebacz K, Greppin H, Degli Agosti R (1999) Repetitive action potentials induced in the liverwort Conocephalum conicum (L.). Arch Sci 52:187-198

Fromm J, Lautner S (2007) Electrical signals and their physiological significance in plants. Plant Cell Environ 30:249-257

Hayashi Y, Nishiyama H, Tanoi K, Ohya T, Nihei N, Tanioka K, Nakanishi TM (2004) An aluminum influence on root circumnutation in dark revealed by a new super-HARP (high-gain avalanche rushing amorphous photoconductor) camera. Plant Cell Physiol 45:351-356

Hedrich R, Salvador-Recatala V, Dreyer I (2016) Electrical wiring and long-distance plant communication. Trends Plant Sci 21:376-387

Krol E, Trebacz K (2000) Ways of ion channel gating in plant cells. Ann Bot 86:449-469 
Krol E, Dziubinska H, Stolarz M, Trebacz K (2006) Effects of ion channel inhibitors on cold- and electrically-induced action potentials in Dionaea muscipula. Biol Plant 50:411-416

Krol E, Plachno BJ, Adamec L, Stolarz M, Dziubinska H, Trebacz K (2012) Quite a few reasons for calling carnivores 'the most wonderful plants in the world'. Ann Bot 109:47-64

Król E, Dziubińska H, Trębacz K (2010) What do plants need action potentials for? In: DuBois ML (ed) action potential. Nova Science Publisher, New York, pp 1-28

Kurenda A, Stolarz M, Zdunek A (2015) Electrical potential oscillations-movement relations in circumnutating sunflower stem and effect of ion channel and proton pump inhibitors on circumnutation. Physiol Plant 153:307-317

Macedo FCO, Dziubinska H, Trebacz K, Oliveira RF, Moral RA (2015) Action potentials in abscisic acid-deficient tomato mutant generated spontaneously and evoked by electrical stimulation. Acta Physiol Plant 37:207

Millet B, Badot P (1996) The revolving movement mechanism in Phaseolus; New approaches to old questions. In: Greppin $\mathrm{H}$, Degli Agosti R, Bonzon M (eds) Vistas on Biorhythmicity. University of Geneva, Geneva, pp 77-98

Moran N (2007) Osmoregulation of leaf motor cells. FEBS Lett 581:2337-2347

Moshelion M, Becker D, Czempinski K, Mueller-Roeber B, Attali B, Hedrich R, Moran N (2002) Diurnal and circadian regulation of putative potassium channels in a leaf moving organ. Plant Physiol 128:634-642

Mousavi SAR, Chauvin A, Pascaud F, Kellenberger S, Farmer EE (2013) Glutamate receptor -like genes mediate leaf-to-leaf wound signalling. Nature 500:422-426. doi:10.1038/ nature 12478

Paszewski A, Dziubinska H, Trebacz K, Zawadzki T (1982) Electrical activity of the liverwort Conocephalum conicum. Method of investigation and general characteristics of excitation. Physiol Plant 54:83-87

Salvador-Recatala V (2016) The AKT2 potassium channel mediates $\mathrm{NaCl}$ induced depolarization in the root of Arabidopsis thaliana.
Plant Signal Behav 11(4):e1165381. doi:10.1080/15592324. 2016.1165381

Salvador-Recatala V, Tjallingii WF, Farmer EE (2014) Real-time, invivo intracellular recordings of caterpillar-induced depolarization waves in sieve elements using aphid electrodes. New Phytol 203:674-684

Shiina T, Tazawa M (1986) Action potential in Luffa cylindrica and its effects on elongation growth. Plant Cell Physiol 27:1081-1089

Sibaoka T (1991) Rapid plant movements triggered by action potentials. Bot Mag Tokyo 104:73-95

Stahlberg R, Stephens NR, Cleland RE, Van Volkenburgh E (2006) Shade-induced action potentials in Helianthus annuus L. originate primarily from the epicotyl. Plant Signal Behav 1:15-22

Stankovic B, Witters DL, Zawadzki T, Davies E (1998) Action potentials and variation potentials in sunflower: an analysis of their relationships and distinguishing characteristics. Physiol Plant 103:51-58

Stolarz M, Krol E, Dziubinska H, Zawadzki T (2008) Complex relationship between growth and circumnutations in Helianthus annuus stem. Plant Signal Behav 3:376-380

Stolarz M, Krol E, Dziubinska H, Kurenda A (2010) Glutamate induces series of action potentials and a decrease in circumnutation rate in Helianthus annuus. Physiol Plant 138:329-338

Stolarz M, Zuk M, Krol E, Dziubinska H (2014) Circumnutation Tracker: novel software for investigation of circumnutation. Plant Methods 10:24

Stolarz M, Król E, Dziubińska H (2015) Lithium distinguishes between growth and circumnutation and augments glutamateinduced excitation of Helianthus annuus seedlings. Acta Physiol Plant 37:1-9

Vandenbrink JP, Brown EA, Harmer SL, Blackman BK (2014) Turning heads: the biology of solar tracking in sunflower. Plant Sci 224:20-26

Zawadzki T, Dziubinska H, Davies E (1995) Characteristics of action potentials generated spontaneously in Helianthus annuus. Physiol Plant 93:291-297 